\title{
Exploring the Pedagogical Practices used in Competence Based Education Training of Nurses and Midwives in Uganda
}

\author{
Milly M. Kabanga, Christopher B. Mugimu, PhD, Joseph Oonyu, PhD \\ College of Education and External Studies, \\ Makerere University
}

\begin{abstract}
In Uganda CBE was introduced in 2006 and since then no study has been done to find out its suitability in the preparation of competent nurses and midwives. In recent years, there is increased attention given to Competence Based Education (CBE) in nursing and midwifery training programs as means of improving quality healthcare services. The use of suitable pedagogical practices in CBE training is critical for assisting students to effectively learn important concepts needed for their practice. The purpose of this study was to explore the suitability of pedagogical practices utilized in the CBE training programs in Uganda. The study was conducted from March to June 2015, at Mulago National Referral Hospital (MNRH). Concurrent mixed methods were used to gather both quantitative and qualitative data from respondents. A total of 193 participants were drawn from nurses and midwives trained under the CBE program and other key stakeholders, namely school principals, nursing and midwifery tutors, hospital administrators/medical consultants, officials at both Uganda Nursing and Midwifery Examination Board (UNMEB) and Uganda Nurses and Midwives Council (UNMC). Results by the majority of nurses and midwives who benefitted from the $\mathrm{CBE}$ training, revealed that the pedagogical practices used were suitable to enable them become competent nurses and midwives. However, the opinion of some key stakeholders differed. They noted that the implementation of suitable pedagogical practices in CBE training faced numerous challenges that needed to be addressed. These challenges included inadequate resources in terms of medical supplies and equipment as well as insufficient support given to trainees during clinical training due to shortage of staffing. This resulted into big workloads due to large student numbers, coupled with insufficient follow up by their tutors who are poorly motivated and have negative attitudes towards students. The study recommended the necessity to sensitize all implementers and stakeholders on the best pedagogical practices for CBE programs. There is also need to improve resources and conditions of students' practicum training sites as well as to recruit more clinical instructors to specifically support the increasing numbers of students during their practicum training sites.
\end{abstract}

Keywords: Competency-Based Education, Pedagogical-Practices, StudentCentered Learning, Teaching Learning Materials, Practicum Placement Sites. 


\section{Introduction}

Nurses and midwives are the backbone of health service delivery worldwide. Due to the critical position they hold in the health sector, emphasis is put on the quality of their training and competences during their preparation for effective service delivery (Barksdale, Newhouse, \& Miller, 2014; Ministry of Health, 2007; MoES, 2012; WHO, 2009) Therefore, increased attention is being given to competency-based education (CBE) in nursing and midwifery training, as opposed to the traditional teacher-based approach. This enhances the preparation of health professionals with right skills required by the dynamic changing labour needs (Chapman, 1999; Frank et al., 2010; Gruppen, Mangrulkar, \& Kolars, 2010). To achieve the right skills for service delivery, it necessitates the use of suitable pedagogical practices during the training that enables students to attain transferable skills from theory to practice (HCCA, 2012). This is the essence of learning-by-doing to achieve the needed practical "knowhow"(Jhpiego, 2010).

The achievement of the practical know-how refers to the learners' ability to correctly perform the expected competences in terms of knowledge, skills, values, and attitudes in the workplace (Anthopoulou, Valkanos, \& Fragkoulis, 2017; Parternership, 2017). The pedagogical practices of concern, include Student-Centered Learning (SCL), Use of Teaching Learning Materials (TLM) such as computers, anatomical models, medical equipment/ supplies; and Placement of trainees in Clinical Practicum Training Sites. This is to ensure that adequately skilled service providers are trained to offer quality health care desired by the world of work (Deißinger \& Hellwig, 2011).

It was earlier hoped that the adopted CBE pedagogical practices provisions introduced in the training would enable the trainees to competently carry out hands-on clinical skills needed in their workplace (Billett, 2016; Chapman, 1999). However, since the inception of CBE pedagogical practices, no study has been done in Uganda to assess the suitability of the instructional reforms applied in the training programs of nurses and midwives. The purpose of the study therefore, was to investigate the suitability of the pedagogical practices used in CBE training programs of nurses and midwives in Uganda.

\section{Literature}

\section{Pedagogical practices and Quality Health Care Service Delivery}

In $\mathrm{CBE}$ training, pedagogical practices refer to the teaching approaches and materials used that are critical to the implementation process of nursing and midwifery training programs. The pedagogical practices when suitably used in the teaching and learning, are built on the philosophy that almost all learners can learn. To make this philosophy work, significant changes require the application of different pedagogical practices. The pedagogical practices of concern for this study are limited to Student Centred Learning (SCL), use of teaching learning materials (TLMs) and conducting practicing skills in clinical placement training sites. 
It is assumed that correctly applying different pedagogical practices in the training is the centre of the learning process that transfers skills for the achievement of the intended out comes. The attainment of the learning outcomes leads to production of highly knowledgeable and skilled healthcare providers (LaLiberte \& Hewitt, 2008). Similarly Uys and Gwele (2005) cites that outcomesbased education (OBE) is competence-oriented and performance to education that is aligned with demands of the work place. To achieve this, the training programs, trainees are engaged in SCL training approaches to enable them to systematically acquire expected competences with an aim of offering quality health services.

\section{(i) Student-Centred Learning Practices}

A Student Centred Learning (SCL) method or approach to training is structured in such a way that the training and assessment of trainees is directed towards achieving specific outcomes. It is concerned with assisting learners to acquire skills and knowledge so that they can perform a task to a specified standard under certain conditions. Bensah, Ahiekpor, and Boateng (2011) asserts that the emphasis is on performing the skill rather than just knowing it. Sullivan and McIntosh (1996) observes that the traditional approach to education is an ineffective system where the goal is to train individuals to perform specific jobrelated skills. Van Horn and Freed (2008) urges that clinical learning activities are the heart of health programs that shape a student into the practice and it is important that practical experience be connected with classroom theory.

This argument is the focus of applying of Student Centred Learning (SCL) approach for acquiring competence from clinical practice for health service delivery. Feldman and McPhee (2007) refers to SCL to be the art of teaching that translates theory into practice. This is a major reform in the education for health professionals. Frenk et al. (2010) points out three generations of education reforms, first generation occurred at the beginning of the 20th century which taught a science based curriculum. The mid-century is the second generation which introduced problem based instructional innovations and the third generation is now needed to be clinical practice based in order to improve professional competencies. This implies that students too have to change from the $20^{\text {th }}$ century trends of the traditional, teacher centred approaches to SCL practices that encourage students to play a more responsible role towards skillsoriented learning for masterly of knowledge and skills.

The two key components in SCL involve a skill being a task or group of tasks performed to a specified level of proficiency, which involves management of the procedure and manipulation of equipment and instruments by trainees during clinical practice. This paradigm emphasizes competencies to achieve the outcomes in the training of health professionals. Thanh (2010) notes that the required skills for professionals are acquired through manipulation of tools and equipment. This approach of SCL renders the learner to be an active participant. The active learning situations which suite SCL include use of different teaching learning materials, such as anatomical models in the skills laboratories with reference of check-lists and learners guides. 


\section{Manipulation of Teaching Learning Materials [i.e. models, equipment, patients, peers]}

In order to effectively transfer theory into skilled practice, a wider range of teaching aids or learning materials (TLMs) are required to facilitate the teaching and learning process (Newble \& Cannon, 2000 ). They are of the view that perhaps the most fundamental use of TLMs is to transfer skills during classroom, practical and / or clinical teaching. Hanrahan (2007) found out that the control the teacher has in teacher-centred methods of instruction, predominantly constrain motivation that leads to involvement of the trainee in the learning process. This argument is in line with the emphasis put on the teaching programs that employ manipulation of TLMs (Sullivan \& McIntosh, 1996). The effective employment of current innovative technological training of health professionals is an area of concern, if the objective is to produce skilled service providers.

\section{(iii) Clinical Placement Training sites}

Placing Trainees in the practicum training sites is a pedagogical practice to bridge the competency gap between the classroom and the clinical area. The purpose is that medical education must prepare trainees for effective practice (Frenk et al., 2010). Redman, Lenburg, and Walker (1999) also assert that competent performance by health care professionals is expected by society. Grundy (2001) notes that nurses qualifying from training programs should be fit for practice. Therefore, the pedagogical practice of placing trainees in clinical practice is for purposes of demonstrating skills for competence. It is hoped that clinical placement attachments prepare students for masterly of competences for service delivery. In the absence of clinical attachment, employers believe that the preparation of nurses and midwives for practice is not adequate on registration.

Frenk et al. (2010) affirms that medical education must adequately prepare trainees for applying skills and that the content that does not contribute to the preparation for practice should be dropped. In support of acquiring skills in the practicing sites, Van Horn and Freed (2008) argue that clinical learning activities are the heart of transferring skills in nursing programs that shape the students for practice. It is therefore important that trainees are placed for practical experience to be linked with their theoretical learning. It has been noted by researchers that the notion of linking competencies in theory and practice of midwifery and nursing training has been the subject of debate for many years and is well documented in the nursing literature (Lauder et al., 2008; Wall, Andrus, \& Morrison, 2014). The attainment of competences for quality service provision is what is expected to be achieved by trainees from clinical placement training sites.

\section{Methods}

\subsection{Design and Sample}

This cross-sectional study adopted a concurrent mixed method design with both quantitative and qualitative data collection methods. A total of 193 respondents participated in the study. These included 102 selected by convenient sampling 
technique from the 143 Nurses and Midwives trained under the CBE program and who were currently working at Mulago National Referral Hospital $(\mathrm{MNRH})$. Thereafter, purposive sampling was used to select a total of 91 key stakeholders, who included; 66 preceptors /ward in-charges who are the immediate supervisors of trainee nurses and midwives during clinical practice participated in FGDs. Twenty five (25) key informants participated in-depth interviews. They included; School Principals, Tutors, hospital administrators/ medical consultants, officials at both Uganda Nursing and Midwifery Examination Board (UNMEB) and Uganda Nurses and Midwives Council (UNMC).

\subsection{Instruments}

The study utilized several research tools including questionnaires, FGD and Indepth Interview guides. The questionnaire consisted of closed-ended questions that were rated on a 3 point Likert scale. Scale 3 represented those who agreed, while score 1 represented those that disagreed on score items regarding implementation of pedagogical practices in $\mathrm{CBE}$ training programs of nurses and midwives for provision of quality healthcare.

\subsection{Data Collection Methods}

Data collection was undertaken from March to April 2015. The key study participants were nursing and midwifery service providers who had undergone the CBE curriculum training from 2008 to 2014. They were requested to individually complete the questionnaires. In-depth interviews and FGDs were scheduled with key informants within the same period.

On the other hand, data from FGDs was collected from nurses and midwives working in the specific critical areas of clinical practice at MNRH, where handson competences are required for life saving tasks such as, managing head injuries and conducting baby deliveries. Three participants from each ward were selected according to their order of seniority. Two FGDs were held on each day. Data collection exercises were carried out for five days. The groups comprised of 9-10 preceptors/ward In-Charges. The principal investigator invited participants during lunch breaks, to avoid interruption of their busy schedules. Participants received an informed consent form, which they signed to confirm their acceptance to participate in the study. The FGDs were conducted between 45-60 minutes and participants were given refreshments in compensation for their lunch break. The gathered data was audio recorded, stored on a computer as well as external drives.

\subsection{Data Analysis}

Quantitative data from the questionnaires with a 3 Likert scale of Disagree, Undecided and Agree was presented using tables and figures, for ease of analysis using (SPSS) version 21. Descriptive statistics were generated in form of frequencies and percentages. On the other hand, qualitative data from FGDs and in-depth interviews was analyzed under common themes and subthemes, informed by the Grounded Theory. The common themes and subthemes were generated from the relevant written verbatim quotations and statements. 


\subsection{Ethical Considerations}

The study was approved by both the postgraduate research committee of Makerere University College of Education and External Studies (CEES) and Mulago National Referral Hospital (MNRH) administration. Clearance was also given by Mulago Research Education Committee (MREC). An introductory letter with MREC: 694 was presented to the participants. In addition, the purpose of the study, confidentiality, voluntary participation, and freedom to withdrawal, were clearly explained to the participants ahead of signing a consent form to confirm their acceptance to participate in the study.

\section{$4 \quad$ Results}

\subsection{Suitability of Pedagogical Practices in CBE training programs of}

\section{Nurses and midwives}

Participants' opinion regarding suitability of the pedagogical practices applied in CBE training programs of nurses and midwives was assessed. The responses focused on three parameters in this study namely; Student-Centered Learning (SCL), Use of Teaching Learning Materials (TLMs) namely; (Skills/Computer laboratories, medical models, manikins and equipment) and Placement of Trainees in Clinical Practicum Training Sites.

\subsubsection{Suitability of SCL Pedagogical Practices Used in CBE Training}

Table 1: Student-Centered Learning (SCL) Exposure

\begin{tabular}{llccc}
\hline & The Student Practices I was exposed to: & Disagree & Undecided & Agree \\
\hline 1 & Empowered me to own my learning & $5.9 \%$ & $5.9 \%$ & $88.2 \%$ \\
2 & Facilitated my peer learning & $1.0 \%$ & $8.8 \%$ & $90.2 \%$ \\
3 & Promoted my experiential Learning i.e. hands on practice & $3.9 \%$ & $2.9 \%$ & $93.1 \%$ \\
4 & Improved my problem solving skills & $4.9 \%$ & $14.7 \%$ & $80.4 \%$ \\
5 & Enhanced my communication skills & $0.0 \%$ & $11.8 \%$ & $88.3 \%$ \\
6 & Improved my critical thinking skills & $5.9 \%$ & $14.7 \%$ & $79.5 \%$ \\
7 & Provided me with lifelong learning skills & $9.8 \%$ & $5.9 \%$ & $84.3 \%$ \\
\hline
\end{tabular}

The results from table 1 revealed that the majority of CBE trained responses (93\%-79\%) were in agreement that the SCL instructional method was suitable for their training programs. 
Respondents from the FGDs also revealed that SCL training approach enabled trainees to own their learning to carry out assigned tasks. This is as reported by one of the wards in charge who supervise trainees in practice as is reflected in the following quotation: "They do because even after teaching them when you give them an assignment to do, they take responsibility to go and do it such that they can present it the next day" (FGD1). This implied that trainees gained an insight to individually work on the given tasks and ably presented to their supervisors for feedback which is a positive move towards implementation of SCL method.

Another participant also supporting the suitability of SCL approaches pointed out the issue of students working independently in peer groups to prepare procedures. This is reflected in the following quotation:

"Yes, it's true some of the students have that independent type of working, when they come in the morning they set trolleys"(FGD2). This implied that some trainees had attained the skills at proficiency level and could prepare procedures in the clinical setting and this is what is expected from them in service delivery.

Similarly a participant was of the view that boys showed more interest in attending to demonstrations given by their supervisors than girls. This is shown in the quotation below:

"Boys are more interested, when you demonstrate for them a procedure, the next day they will do it. The challenge is on the training schools because some girls have negative attitude as they may not be motivated to join the profession" (FGD4). This is a new discovery that brings boys on board in an area of study which is mainly dominated by the females. Boys although fewer than girls, seem to be more interested in the profession than girls. This is an area for another study to explore why boys are more interested in the profession than girls.

On the other hand some respondents expressed concerns over the risk of beginners using SCL before introducing theory. This is given in the following quotation:

"For the beginners it becomes risky to adapt SCL because trainees have not yet learnt anything in theory although it makes them confident" (FGD1). This is an indication that some supervisors of the trainees are still teacher based oriented. At the skills acquisition level, beginners are supposed to only observe skills being performed while using a learners guide therefore there is need for sensitization of supervisors on SCL training approaches' for standardization.

Similarly another participant from the same group noted that the method was done at a minimal level by the faculty, arguing that the CBE trainers themselves are not yet competent with applying SCL training methodologies. This was pointed out in the quotation below:

"It's done at minimal level, as people concerned with the training are not yet competent with the competence based student learning yet In most cases teachers take charge of the student's learning" (FGD1). This is a challenge where the trainers themselves are perceived to be lacking competency in CBE pedagogical training methods. This implies that they continue teaching using traditional teacher based training 
approaches. The teacher based traditional trends applied by the trainers compromise SCL approaches of hands-on performance required for skilled nurses and midwives for practice.

Similarly, in one of the in-depth interviews, it was observed that students themselves were teacher-dependant because they depend more on the given notes. This is shown in the following quotation:

"Our students are not yet well motivated for student centred learning and tend to depend most on our notes that even when we give them assignments they tend to be reluctant saying that after all we have teachers who will give us the notes" (ID 02T04). This is a worrying situation where the traditional teacher based training produces theoretical trainees, yet what is required are nurses and midwives who can confidently perform in practice to address the health needs.

However another ID also noted that there was a problem in the implementation of this method by trainers, as such they divert from the CBE curriculum and follow the traditional practices. This is highlighted in the following quotation:

"We have a problem because the curriculum states SCL methods but unfortunately in practice these methods are not followed. Largely the lecture method is used" (ID 09C02). This implies that the trainers themselves are not competent to manage SCL approaches, hence, hence the need for orientation of the implementers.

Another ID interview participant cited the problem of big student numbers as a hindrance to implementing the SCL method, citing that many students being handled in a class makes it difficult to manage the process. This is shown in the following quotation:

"The teaching approach does not allow SCL due to huge numbers of students and if you use it, control of students in a class is too difficult" (ID 03H04). This is a challenge that requires skills of managing big numbers in the SCL method. It is also a policy issue to regulate the numbers of student nurses and midwives admitted to training institutions.

\subsubsection{Suitability of TLMs Pedagogical Practices Used in CBE training}

Table 2: Use of pedagogical TLMs to Improve Skills

\begin{tabular}{llccc}
\hline & Use of Pedagogical TLMs improved my: & Disagree & Undecided & Agree \\
\hline 1 & Acquisition of competences in skills laboratory & $19.6 \%$ & $8.8 \%$ & $71.6 \%$ \\
2 & $\begin{array}{l}\text { Hands on the anatomical models for achieving practical } \\
\text { skills }\end{array}$ & $17.6 \%$ & $17.6 \%$ & $64.7 \%$ \\
3 & $\begin{array}{l}\text { Practices on the computer learning for acquiring of ICT } \\
\text { skills }\end{array}$ & $11.8 \%$ & $0.0 \%$ & $88.2 \%$ \\
$4 \quad \begin{array}{l}\text { Ability for Independent learning and referencing with } \\
\text { text books }\end{array}$ & $6.3 \%$ & $6.3 \%$ & $87.5 \%$ \\
$\quad \begin{array}{l}\text { Application of other teaching learning materials for } \\
\text { linking theory to practice }\end{array}$ & $3.9 \%$ & $0.0 \%$ & $96.1 \%$ \\
\hline
\end{tabular}


The results by responses of former CBE trainees revealed that the use of TLMs namely; (Skills laboratory / computer laboratory, text books, anatomical models, manikins and others e.g. equipment/instruments) were suitable for transferring skills to the trainees during their training programs as reflected in table 2 . The high percentage of agreement i.e. (65-96\%) of respondents clearly shows suitability/usefulness of the TLMs used.

Findings from the FGDs who are the students ward supervisors were of mixed opinion. Some participants supported use of the available gadgets while others felt that there were limitations. As such, one of the participants in support of the suitability of teaching resources narrated that students frequently used them to save patients' lives. This is reflected in the following quotation: "Yes they are used because these are things they use every day especially the Ambu-bag for resuscitation of patients" (FGD3). This implies that trainees acquired resuscitation competences through managing critically ill patients in real life learning experience. The more students practice the better they become proficient for providing patient care.

Another supervisor of students in agreement with the suitability in use of teaching learning medical equipment, attributed it to the availability of medical equipment and materials for students' exposure at the patient's bed-side. This is reflected in the following quotation: "The available materials are at the student's exposure and if a student is really keen, he or she can learn how oxygen is administered to the patient and with its full apparatus. Full monitoring of patients can be done using bed-side monitors which are at our exposure" (FGD 5). This signifies the importance of having equipment and materials in good working condition, to aid students consolidate skills acquired from the skills laboratory to link with the hands on practice in the clinical setting.

However findings from some FGDs and IDs generally pointed out that much as the TLMs are significant in imparting skills for training, they are either inadequate or inaccessible due to various reasons like; security, fear of damage or losing them as well as big student numbers. The general inadequacy of medical supplies and or equipment prevails and is reflected in the following quotations:

"Not adequate, we improvise. We have observation charts but no thermometers. Blood pressure machines are at times not functional" (FGD1). Another participant on the same issue also commented:

"Not adequate where I work, we have to be with a disinfectant, but most times I run out of jik, sometimes you end up using liquid soap with no jik" "stock out is making us fail" (FGD4). This situation of solving the issue of inadequacy with improvisation is not good when the goal is for trainees is to see the real training and learning aids that assist them to understand their use.

Similarly, some of the participants noted that the fear to lose or sustain damage of the equipment leads to their being inaccessible in to students. This is shown in the following quotations: 
"In maternity-ward we have models like the manikin, used to teach students how to resuscitate a new born baby who is not well, to help him breathe. The materials are available and I have control over them but students cannot access them outside the teaching time because of security reasons" (FGD1). This implies that students do not get enough time to practice using simulations on the models during their own time to consolidate theory with practice. This compromises the students' ability in acquiring the desired skills for quality practice.

Another participant from the same ward commented that the fear of damage or loss of the only available equipment, necessitated a supervisor to be present while students use it, as is reflected in the following quotation:

"We have a urinometer but getting it out and it breaks up is a loss unless it is used in the presence of a supervisor" (FGD1). This scenario renders trainees to compete for a single equipment available. As a result some students may fail to get a chance to learn how to use it, given the fact that it must be used in the presence of a supervisor, to the which points to necessity for more supplies.

Another ward supervisor attributed failure to use TLMs due to big student numbers where there is reluctance by trainers to use available equipment. This is reflected in the following quotation: "Staff are reluctant to use them, having access of 100 students to be shown a model of a heart is tedious and it would be better to lecture to them." (FGD1). This situation brings about missing out on clarification of understanding, as a result, trainees resort to memorizing facts which is learning by heart as opposed to learning by touch to attain skills for quality service delivery.

Another ward supervisor commenting on scarcity of teaching aids was of a view that students bring visual aids to supplement the TLMs. This is reflected in the following quotation: ".....For teaching materials, when giving health education talks, students have to bring visual aids to facilitate their talk" (FGD3). This is a good innovation where trainees are encouraged to prepare health education talks using locally available and economical visual aids, for attainment of competences in their practice.

Similarly one In-depth interview also revealed that use of TLMs was suitable much as there were not enough equipment in clinical wards as reflected in the quotation:

"Very good however when you demonstrate a procedure at school, as students go to the wards for practice they may find a different picture because wards don't have enough equipment" (ID 06T03). This situation creates a miss-match between classroom instruction and clinical teaching whereby students fail to properly transfer skills obtained from the skills lab to the clinical setting. This situation makes it difficult for learners to link theory to practice for provision of quality health care.

Furthermore the same participant commented that use of ICT is affected by the computer laboratory not being open all the time for the learners' usage. She stated that: "Use of ICT positively contributes to students learning as it helps the students to get information easily, learn and love studying. However students can only access the computer lab when the lab attendant is available (ID 06T03)". This implies 
that students do not get enough time to use the computer lab, consequently overcrowding of the lab when it is open, which leads to inadequate exposure to the use of a computer lab hence producing incompetently trained professionals in ICT. There is therefore need for proper management of the computer lab in order to benefit the learners.

\subsubsection{Placing Students in Clinical Placements Training sites}

Table 3: Clinical placement enhancement of skills:

\begin{tabular}{llccc}
\hline & $\begin{array}{l}\text { Clinical placement Training Sites enhanced my } \\
\text { ability to: }\end{array}$ & Disagree & Undecided & Agree \\
\hline 1 & $\begin{array}{l}\text { Bridge the competence gap between classroom } \\
\text { theory and clinical practice }\end{array}$ & $0.0 \%$ & $0.0 \%$ & $100.0 \%$ \\
2 & Execute evidence-based practice in real world & $0.0 \%$ & $0.0 \%$ & $100.0 \%$ \\
3 & Acquire communication and interpersonal skills & $0.0 \%$ & $6.2 \%$ & $93.8 \%$ \\
4 & Assist with workloads for completion of clinical tasks & $0.0 \%$ & $5.9 \%$ & $94.1 \%$ \\
5 & $\begin{array}{l}\text { Organize adequate time for acquiring expected } \\
\text { clinical skills for practice }\end{array}$ & $15.7 \%$ & $0.0 \%$ & $84.3 \%$ \\
6 & $\quad$ Attain the required clinical skills for my practice & $0.0 \%$ & $5.9 \%$ & $94.1 \%$ \\
$7 \quad \begin{array}{l}\text { Obtain adequate frequencies in clinical practice to } \\
\text { consolidate the needed skills for service delivery }\end{array}$ & $16.7 \%$ & $5.9 \%$ & $77.4 \%$ \\
\hline
\end{tabular}

Results revealed that the method was suitable for their training. They also noticed that the method enabled them bridge the gap between theory and practice, by acquiring evidence-based practice, communication skills, and learned to assist with workloads. This is reflected by the high percentage of agreement i.e. (77-100\%) as shown in table 3 Below.

Similarly, some respondents from FGDs and IDs shared the views that trainees acquire skills from the practicum training sites to link theory to practice.

On the same note, one of the FGDs citing the importance of clinical placements, commented that trainees are to skills oriented by being in practicum sites, as expressed in the following quotation:

"We orient them as they first come. I get time to teach them on topics. When it comes to practicals I do take them to the room and show them the types of vaccines and how they are administered" (FDG3).

This implies that clinical attachment exposes trainees to real hands on learning experiences which can only be acquired from clinical placement. For example 
one of the in-depth interviews reported that the training sites expose trainees to various health conditions in their domain. This is reflected in the following quotations:

"Students learn a lot of things from clinical areas and are exposed to various pathologies and are able to do a lot of things. They also interact with doctors and get much from them" (ID 01H01). The implication of this is that students gain a lot from clinical placement to link theory learnt in the classroom to practice. During clinical learning interactions, they gain a broader picture for acquiring expected competences.

Nevertheless, there are FDGs and IDs who raised issues of concern regarding suitability of the clinical practicum training sites such as inadequacies of resources, understaffing, workload, negative attitude, and follow up for supervision of trainees during clinical placement. These concerns impact on students' support to attain competences from clinical areas.

One of the FDGs regarding the issue of equipment scarcity, reported that they improvise to get the procedure done, as stated in the following quotation:

"There is a gap in the organization of hospitals because we expect students to learn skills though we sometimes don't have equipment to use. We may say we use a trolley for a certain procedure but when they come to the ward we do a lot of improvisation which also affects them" (FDG5).

On the same note, another participant also said that big student numbers have impact on the limited resources they have, to support students' clinical learning. This is what he said:

"With big student numbers like if you have about 15 students, the resources like gloves are small and 2 boxes may not cover the whole week" (FGD5). This implies that students also consume what is meant to be used in clinical practice for patients. There is therefore to ensure students have supplies to use.

One of the in-depth interview respondents reported that as part of shortage of resources, understaffing leads to trainees being seen as a labor force to assist with the workload thereby compromising their ability to learn. This is as reflected in the quotation below:

"It depends on numbers of staffing. We are understaffed and a lot is expected of us so follow up may not be as it is expected to be because of work and a few numbers. The challenge is because in the schools the tutors are under staffed and even in the wards there is understaffing" (ID 02T04). The issue of understaffing has been a longstanding challenge in clinical practice in Uganda. This situation means that students are inadequately attended to. There is need for proper management of students' clinical placement schedule. This is, realized in the following quotations;

"Poor follow up by clinical instructors and preceptors because we have not made a program for that, and we have not thought about it" (FGD 5). 
Another participant indicated that members of staff have no time for giving students support, instead of teaching them, they load them with work, as indicated in the following quotation:

"We don't get enough time because of shortage of nurses and resources. There are some units that have made it a tradition that when they get students they load them with work and yet they are supposed to teach them" (FGD 4). This means that students, instead of being supported for clinical learning, they are sharing the workload. This occurrence needs to be addressed to make clinical learning beneficial to learners.

Findings from the In-depth interviews also revealed workload and understaffing as contributory factors to inadequate support of trainees during clinical practice as reflected in the quotations below:

"Preceptors don't have enough time to spend with students because they have their duties to cover and at the same time have students to help" (ID 01EB06). In this case students become an extra burden for staff with the existing workload. This emphasizes the need for recruiting clinical instructors to specifically support the trainees in clinical practice.

Another respondent from FGD cited another issue of inadequate follow-up of their students when placed in clinical training sites, and some students abscond from the site. This is indicated in the following quotation:

"Follow up by tutors is not good. Sometimes students come and they are not followed up. If you get challenges with them and you contact the training schools nothing is done. Some students may not even appear for placement" (FGD3).

Another supervisor also noted that follow up of students by preceptors is equally rare and this is what she said: "Not quite often do preceptors follow up but at least in a week you could try to see what they do. Follow up is rare due to too much work on the ward" (FGD6). This implies that preceptors who are expected to follow up trainees also fail to execute their role. This situation affects support given to students learning while in clinical placement.

However one in-depth interview also attributed this situation to understaffing and commented as follows:

"Heavy workload; you cannot give quality care when you one midwife faced with 100 patients as well as having to mentor students" (ID 10H01).

Another participant also reported big student numbers in the practicum training sites to be an issue of concern in clinical practice. This is reflected in the following quotation:

"Follow up of students is not easy due to the big student numbers. It is difficult supervising fifteen (15) students at ago" (FDG1).

This situation of overcrowding renders trainees to be inadequately supervised and given practical support for attainment of clinical skills. 
The issue of attitude as a result of low staff motivation also came up during indepth interviews, as a contributory factor on towards inadequate support given to students during clinical training. This is reflected in the following quotation:

"Preceptor's poor attitude towards student is due to heavy work load and is partly as a result of low motivation which may not be necessarily because of money but poor working conditions and patients who are not patient as well as students who put a lot of demand on staff" (ID 10H01).

Another in-depth interview noted that much as students try their best in clinical practice, the clinical staff is frustrated by the faculty/ teaching staff not supervising them. This is as reflected in the quotation below:

"Students try to do what they can, the challenge is inadequate supervision by tutors though there are mentors who are trying to do the work but still it is not adequate because of low motivation of clinical staff attributed to by poor clinical working environment and remuneration creating bad attitudes towards students. Some staff abuse students" (ID 09C02). This implies that low motivation of staffs resulting into bad attitudes is coupled with low motivation due to poor working environment and conditions which make them develop bad attitudes towards students. This jeopardizes students' exposure for consolidation of clinical skills.

Another participant raised the issue of fear, that students are faced with fear of those in clinical practice as well as the ability to perform on patients. Consequently trainees develop a negative attitude towards clinical placement. This is as applied in the following quotation:

"Most students come with a positive attitude but have fear which makes them fear and develop a negative attitude. This fear may be about the nurses they meet during clinical attachment and even the experiences" (FDG4). This further implies that when students are faced with bad attitudes of practicing staff as well as scaring procedures in clinical practicum training sites, this affects their keenness to cope with the situation, which makes them lose interest leading to fear of clinical practice.

Following up with the FGDs and IDs, eight themes that emerged from CBE Pedagogical practices include; resources, management, Gender, Perception, motivation, attitude, innovation and competency.

\section{Discussion}

This study assessed suitability of pedagogical practices in the CBE training programs of nurses and midwives for the provision of quality health care. The pedagogical practices of concern included, Student centred learning (SCL), Use pedagogical Teaching Learning Materials (TLMs) and placement of trainees in practicum training sites access. Findings of this study revealed that the pedagogical approaches were suitable to link theory to practice to achieve the intended outcomes. This implies that the trainees achieved the pre-determined competencies for the $\mathrm{CBE}$ training programs. This enabled them to be competent in offering the desired skills for service delivery (Pijl-Zieber, Barton, Konkin, Awosoga, \& Caine, 2014). This is consistence with the increasing demand for 
contemporary nurses and midwives required for quality service delivery all over the world of work, especially in developing countries. Furthermore, the quality of healthcare services is dependent mainly on how well the training programs are implemented to produce service providers with the expected competences that address the healthcare needs (Uys \& Gwele, 2005). Evidence indicates that a well-trained, diverse nursing workforce improves the quality of health care, patient outcomes, access to health care and decreases the disease burden to save lives (Frenk et al., 2010; WHO, 2009). This is what was emphasized by Florence Nightingale, founder of nursing, who campaigned in the mid-1800s that good nursing care saves lives and good nursing care depends on well-educated nurses (Frenk et al., 2010). In addition, Morolong and Chabeli (2005) pointed out that health care systems generally demand competent nurse practitioners. It is on this basis that this study explored the suitability of the pedagogical practices that were limited to student-centered learning, manipulating teaching learning materials and placement of students in clinical practice, used in the CBE training programs of nurses and midwives to produce competent health service providers.

\section{Student-Centered Learning pedagogical practice}

The pedagogical practice of SCL in CBE training programs of the nurses and midwives was found suitable to promote expected competences to students. Through applying SCL methods, students became active learners to gain an insight to work independently on their own with peer learning. They were also able to acquire the needed skills through hands-on experiences, communication, critical thinking and lifelong learning for practice. This is what is expected to be achieved when the concept of SCL is well understood by stakeholders and implementers. If this is realized, it could be the basis for achieving the fourth and fifth Sustainable Development Goals (SDG) by year 2030. Thus, SCL methods are viewed to be critical in providing learners with expected competences for performing a job (Frenk et al., 2010; Thanh, 2010).

However, there were some professional issues regarding implementation of SCL raised by a few stakeholders. These include nursing administrators from Ministry of Health, wards-in-charge known as preceptors who help trainees in clinical practice and their trainers. They argued that there were challenges in the implementation of this new training approach. They also noted that SCL method had training gaps that need to be addressed. This is in line with a study done by Dole, Bloom, and Kowalske (2016) who reported obstacles that stood in the way of teachers' successful implementation of problem-based learning, which is another form of SCL approach. This is true because results revealed that most of the stakeholders were not oriented on CBE training neither were they well acquainted with SCL practices. It is not surprising that these professionals continue to embrace the traditional didactic-based training approaches familiar to them. Consequently most of them have tended to fall back towards the traditional teacher and content based training approaches. Yet, the traditional training approaches make a learner a non-performer, inactive/passive recipients of knowledge and therefore unable to translate theory to practice (Mabuda, 2009). The teacher based practices known to the stakeholders are not the best 
approach for enhancing practical skills if the goal is to produce nurses and midwives who can independently perform in the practice (Kolb, 1981; LaLiberte \& Hewitt, 2008; Rainey \& Kolb, 1995). There is need therefore to sensitize the stakeholders on the new training approaches to enable them support reforms that change from the traditional didactic centred teaching approaches to providing learners with expected competences for performing a job (Frenk et al., 2010; Thanh, 2010).

\section{The Use of pedagogical Teaching and Learning Materials}

The pedagogical practice in terms of manipulating Teaching Learning Materials (TLMs) for example computer laboratories, medical models and equipment were revealed to be suitable in the training programs of nurses and midwives. These instructional materials aided students to consolidate skills by allowing them to practice over and over again without harming the patients (Alinier, Hunt, Gordon, \& Harwood, 2006; Mutwali et al., 2015). Most students become interested in use of TLMs, to avoid shortcomings of harming real patients before they have acquired skills competence. This implies that these instructional aides are very critical in the training of nurses and midwives because the study realized that they improve abilities of students to attain skills during the learning process (Jhpiego, 2010). This is in line with the Chinese saying that when I hear I forget, when I see I remember and when I do I know (Jhpiego, 2010).

Other studies also revealed that simulation enables trainees gain additional knowledge, critical thinking ability, satisfaction and confidence (Cant \& Cooper, 2010). This is what is expected of our trainees to be in our set up. In the same context other scholars indicate that simulated learning in the clinical or demonstration skills laboratory prepares students to be proficient before working on real patients in a real situation (Ricketts, 2011; Wall et al., 2014). This transformation from skills competence level to proficiency level is referred to as the art to translate classroom theory into practice in order to produce skilled service providers for offering quality health care (Anthopoulou, Valkanos, \& Fragkoulis, 2017; Feldman \& McPhee, 2007). This is possible with the application of suitable instructional aids guided by reference materials or text books. This is what is anticipated to occur in the modern training of the contemporary nurses and midwives for acquiring proficiency in skills for provision of quality health services.

Similarly, the same stakeholders revealed the challenges that were faced during the use of this training method which included; overwhelming student numbers, under staffing, and lack of equipment and supplies. These need to be addressed by the policy makers to enable effective use of pedagogical practice for quality training. Improvisation for equipment and supplies quite often has become a normal practice. In so doing, for example, sometimes improvisation of equipment during practical sessions may undermine the trainees' ability to grasp ideal skills that are skill required in the real life situation. This tendency results into producing inadequately trained personnel for the provision of quality health care. This implies that incompetent service providers continually are being produced who will fail to address the reduction of maternal and infant 
mortality rates to achieve the Sustainable Development Goals (Ministry of Health, 2007; MoES, 2012). This phenomena has to be given agent attention by the concerned authorities for suitable training in order to deliver quality services in this country.

\section{Placement of Trainees in practicum Clinical Training Sites}

It was also important to ascertain suitability of pedagogical practices in terms of placing student nurses and midwives in clinical practicum training sites for acquiring the intended competences for service delivery. The study revealed that placing students in practicum clinical training sites is suitable to impart the required skills to bridge the competency gap between the classroom instruction and clinical area. This implies that the execution of this pedagogical practice is intended for the achievement of the know-how for performing skills in preparing trainees for practice (Redman et al., 1999; Van Horn \& Freed, 2008). Implying that this process leads to highly knowledgeable and skilled health professionals required for the delivery of quality health care (Harden, 2009; LaLiberte \& Hewitt, 2008). This is what is needed in the transformation of CBE training for acquisition of expected skills for service delivery.

Furthermore, the same study revealed issues that interfere with proper implementation of this method by stakeholders. These are in form of inadequacy of resources, understaffing leading to heavy workload, poor staff and student attitudes and lack of capacity building in skills for clinical training. These challenges are not new, several studies found similar constraints in clinical setting. This remains a big challenge that needs to be addressed in our set up (Ayo \& Ndetaulo, 2009; Kigonya, 2004; Magobe, Beukes, \& Muller, 2010; Okoronkwo, Onyia-Pat, Agbo, Okpala, \& Ndu, 2013; Zakari, Hamadi, \& Salem, 2014).

The stakeholders also revealed that students in clinical practice do not get the support they require. This is because supervisors/preceptors in clinical practice lack the capacity to effectively teach students as they have not been oriented in this CBE training approach (Cheraghi, Salasli, \& Ahmadi, 2008; Okoronkwo et al., 2013). This explains the urgent need for a special capacity building of clinical teachers to assist trainees in clinical practice, as well as employing a cadre of clinical teachers to follow up trainees during their clinical practice.

Furthermore, the clinical supervisors were found not well motivated to teach. Other studies have as well documented lack of financial incentives for preceptors, lack of equipment and other relevant materials for proper teaching, poor working conditions and lack of opportunities for knowledge update (Eta, Atanga, Atashili, \& D'Cruz, 2011; Hakimzadeh, Ghodrati, Karamdost, Ghodrati, \& Mirmosavi, 2013; Kigonya, 2004; Okoronkwo et al., 2013). This situation may lead to inadequate clinical support given to students for performing clinical skills. Thus compromising their acquisition of skills for the work place.

The issue of large student numbers in clinical practice as compared to the prevailing resources have also compromised opportunities of students to acquire the needed skills for effective service delivery and led to poor theory-practice integration (Eta et al., 2011; Kigonya, 2004; Mabuda, 2009; Okoronkwo et al., 
2013; Zhong \& Xiong, 2010). For instance, larger numbers of students contribute to the crowding of the wards or clinics and overstretches the preceptors who are already caring for the many patients, resulting into unsupported students in clinical practice. Unsupported learning of students in clinical placement sites has also been highlighted by many authors (Ayo \& Ndetaulo, 2009; Cheraghi et al., 2008; Hakimzadeh et al., 2013; Mabuda, 2009; Magobe et al., 2010). Similarly Ironside, McNelis, and Ebright (2014) suggest that task completion often over shadows the more complex aspects of learning nursing practice. This situation is very worrying if the goal is to train a competent professional service provider. This creates an unconducive environment for students' clinical attachments and as such makes teaching and learning difficult for acquiring the expected competences.

\section{Conclusion}

Nurses and midwives hold a critical position in the health sector globally. It is not surprising that a lot of emphasis is put on ensuring the quality of their training as health professionals to gain the right skills/ competences required by the dynamic changing labor needs (Frank et al., 2010; Gruppen, Mangrulkar, \& Kolars, 2010). In recent years, Competence Based Education (CBE) has become a common mode of training nurses and midwifes. Its focus on the use of suitable pedagogical practices is fundamental in assisting students to effectively learn important concepts needed for their practice. Therefore, the purpose of this study was to explore the suitability of pedagogical practices utilized in the CBE training programs in Uganda. The findings of the study and foregoing discussion revealed that the pedagogical practices in CBE training programs of nurses and midwives namely student centred learning (SCL), use of teaching learning materials (TLMs) and Students placement in clinical areas, were suitable for preparing competent nurses and midwives to deliver quality healthcare services. However, some stakeholders expressed a few constraints impacting the CBE implementation process. These included inadequacies in resources, insufficient support to trainees during clinical placement by preceptors and faculty staff, large student numbers, inadequate follow up of trainees in clinical practice by their tutors and non-motivated staff with negative attitudes towards students together with increased clinical workload coupled with poor clinical environment. These constraints tend to compromise the use of suitable pedagogical practices in CBE training. Therefore, there is urgent need to address these constraints if the $\mathrm{CBE}$ training programs of the nurses and midwives will continue to be relevant and meaningful in order to produce competent health care service providers. What also came out clearly from the study is that suitability of the pedagogical practices does not necessarily mean that they are effectively used. Therefore, proper orientation of stakeholders on the effective use of the suitable pedagogical practices in CBE is critical.

\section{Recommendations}

In light of the findings of the study the following are recommendations:

1. Stakeholders and implementers of CBE pedagogical practices should be sensitized/orientated to create awareness and adaptation of the methods 
through mentoring and coaching as a continuous professional capacity building scheme.

2. Policy makers should create a budget line to address issues of inadequate staffing, supplies and equipment and to ensure security of the working tools. This will allow students to access them any time for peer practice and sharing of information during clinical placement.

3. Principals of training schools should improve the management of large student numbers and increase students' practicum placement hours by drawing placement schedules with appropriate teacher/student ratios during skills laboratory demonstrations and clinical practicum training. This will strengthen student centred learning for quality training to achieve the desired outcomes.

4. Policy makers should strengthen support and follow up of students during practicum training sites by providing clinical instructors and professional role models to address challenges of poor attitudes and motivation of staff to enhance effective use of pedagogical practices in CBE training.

5. Implementers of $\mathrm{CBE}$ training programs should encourage pedagogical innovations such as using locally made and affordable teaching aids during health education promotion as well as setting up and equipping clinical demonstrating corners in all clinical training sites.

6. School Principals should improve students' access to skills and computer laboratories by recruiting full-time laboratory attendants to support students' access to these facilitates at any time of their convenience.

\section{References}

Alinier, G., Hunt, B., Gordon, R., \& Harwood, C. (2006). Effectiveness of intermediatefidelity simulation training technology in undergraduate nursing education. Journal of Advanced Nursing, 54(3), 1359-1369. doi: doi: 10.1111/j.13652648.2006.03810.x

Anthopoulou, K., Valkanos, E., \& Fragkoulis, I. (2017). The Professional Development of Adult Educators: The Case of the Lifelong Learning Centres (L.L.C) in the Prefecture of Evros, Greece. International Journal of Learning, Teaching and Educational Research, 16(11), 77-91.doi:10.26803/ijlter.16.11.5

Ayo, S., \& Ndetaulo, E. (2009). Factors influencing clinical teaching of midwifery students in a selected clinical setting in Tanzania.

Barksdale, J. D., Newhouse, R., \& Miller, A. J. (2014). The Patient-Centered Outcomes Research Institute (PCORI): Information for academic nursing. Nursing Outlook, 62(3), 192-200. doi:https://doi.org/10.1016/i.outlook.2014.03.001

Bensah, E. C., Ahiekpor, J. C., \& Boateng, C. D. (2011). Migrating from subject-based to competency-based training in Higher National Diploma Chemical Engineering: The case of Kumasi Polytechnic. Education for Chemical Engineers, 6(3), e71-e82. doi:https://doi.org/10.1016/j.ece.2011.04.001

Billett, S. (2016). Learning through health care work: Premises, contributions and practices. Medical Education, 50(1), 124-131. doi:DOI:10.1111/medu.12848 
Cant, R. P., \& Cooper, S. J. (2010). Simulation-based learning in nurse education: systematic review. Journal of Advanced Nursing, 66(1), 3-15.

Chapman, H. (1999). Some important limitations of competency-based education with respect to nurse education: an Australian perspective. Nurse Education Today, 19(2), 129-135.

Cheraghi, M. A., Salasli, M., \& Ahmadi, F. (2008). Factors influencing the clinical preparation of BS nursing student interns in Iran. International Journal of Nursing Practice, 14(1), 26-33.

Deißinger, T., \& Hellwig, S. (2011). Structures and functions of Competency-based Education and Training (CBET): A comparative perspective.

Dole, S., Bloom, L., \& Kowalske, K. (2016). Transforming Pedagogy: Changing Perspectives from Teacher-Centered to Learner-Centered. Interdisciplinary. Journal of Problem-Based Learning, 10(1), 1 - 15. doi:https://doi.org/10.7771/1541$\underline{5015.1538}$

Eta, V. E., Atanga, M. B., Atashili, J., \& D'Cruz, G. (2011). Nurses and challenges faced as clinical educators: A survey of a group of nurses in Cameroon. Pan African Medical Journal, 8(1), 28.

Feldman, J., \& McPhee, D. (2007). The science of learning and the art of teaching. Clifton Park, NY: Thomson Delmar Learning.

Frank, J. R., Snell, L. S., Cate, O. T., Holmboe, E. S., Carraccio, C., Swing, S. R., . . Dath, D. (2010). Competency-based medical education: theory to practice. Medical teacher, 32(8), 638-645.

Frenk, J., Chen, L. C., Bhutta, Z. A., Cohen, J. J., Crisp, L. N., Evans, T. G., . . Zurayk, H. (2010). Health Professionals for a new century: transforming education to stengthen Health systems in an independent world. The Lancet, 376 (9756), 19231958. doi:doi:http://dx.doi.org/10.1016/S0140-6736(10)61854-5

Grundy, L. (2001). Pathways to fitness for practice: National Vocational Qualifications as a foundation of competence in nurse education. Nurse Education Today, 21(4), 260-265. doi:10.1054/nedt.2000.0555

Gruppen, L. D., Mangrulkar, R. S., \& Kolars, J. C. (2010). Competency-Based Education in the Health Professions: implications for Improving Global Health. Commission on Education of Health Professionals for the 21st Century Working Paper.

Hakimzadeh, R., Ghodrati, A., Karamdost, N., Ghodrati, H., \& Mirmosavi, J. (2013). Factors affecting the teaching-learning in nursing education. GSE Journal of Education, 2013, 174-184.

Hanrahan, M. (2007). The effect of learning environment factors on students' motivation and learning. International Journal of Science Education, 20 (6), 737-753. doi:https://doi.org/10.1080/0950069980200609

Harden, R. M. (2009). Outcome- based education: Part 1- An introduction to outcomebased education. 1, 14

HCCA. (2012). Competency Based Training and Assesment: Home and Community Care (HCCA) community care worker human resource kit 2007. last updated November 2012.

Ironside, M. P., McNelis, M. A., \& Ebright, P. (2014). Clinical education in nursing: Rethinking learning in practice settings. Nursing Outlook, 62 (3), 185 -191. doi:https://doi.org/10.1016/j.outlook.2013.12.004

Jhpiego. (2010). Training Skills for Health Care Providers. Reference Manual, one(Third Edition), 167.

Kigonya, E. (2004). Medical education in Uganda-A critique. East and Central African Journal of Surgery, 9(2), 1-4.

Kolb, D. A. (1981). Experiential learning theory and the learning style inventory: A reply to Freedman and Stumpf. Academy of Management Review, 6(2), 289-296. doi:doi: 10.5465/AMR.1981.4287844 
LaLiberte, T., \& Hewitt, A. (2008). Impact: The Importance of Competency- Based training for direct support Professionals Institute on Community Integration (UCEDD), 20(2), 1 - 208.

Lauder, W., Roxburgh, M., Holland, K., Johnson, M., Watson, R., Porter, M., . . Behr, A. (2008). Nursing and Midwifery in Scotland: Being Fit for Practice. The Report of the Evaluation of Fitness For Practice Pre-Registration Nursing and Midwifery Curricula Project. Retrieved from University of Salford, Manchester: http://www.nes.scot.nhs.uk/practice_education/work/evaluation/

Mabuda, B. T. (2009). Student nurses' experiences during clinical practice in the Limpopo Province South Africa. University of South Africa, Pretoria.

Magobe, N. B., Beukes, S., \& Muller, A. (2010). Reasons for students' poor clinical competencies in the primary health care: clinical nursing, diagnosis treatment and care programme. Health SA Gesondheid, 15(1), 1-6.

Ministry of Health. (2007). Uganda Human Resource for Health Strategic Plan 2005-2020: Responding to Health sector Strategic Plan and Operationalising the HRH Policy.

MoES. (2012). Skilling Uganda; BTVET strategic plan 2012/13 to 2021/2. Kamplala: Ministry of Education and sports. .

Morolong, B., \& Chabeli, M. (2005). Competence of newly qualified registered nurses from a nursing college. Curationis, 28(2), 38-50.

Mutwali, I. M., Al_Raheem, N. A., Elhassan, W. A. M., Ibrahim, S. S., Abdulhamid, A., Fadulalbary, E., \& Aglan, A. (2015). Communication skills training through an inter professional education initiative for undergraduate mult-professional students. International Journal of Learning, Teaching, and Educational Research, 13(2), 195-207.

Newble, D., \& Cannon, R. (2000 ). A handbook for teachers in universities and colleges (4 ed.). Abingdon, England: Routledge Falmer.

Okoronkwo, I. L., Onyia-Pat, J.-L., Agbo, M.-A. E., Okpala, P. U., \& Ndu, A. C. (2013). Students' perception of effective clinical teaching and teacher behaviour. Open Journal of Nursing, 3(01), 63.

Parternership, G. S. (2017). Ten Principles of Competency-Based Learning. http://greatschoolspartnership.org/wpcontent/uploads/2017/01/GSP_Ten_Principles_of_CBL.pdf

Pijl-Zieber, E. M., Barton, S., Konkin, J., Awosoga, O., \& Caine, V. (2014). Competence and competency-based nursing education: finding our way through the issues. Nurse Education Today, 34(5), 676-678.

Rainey, M. A., \& Kolb, D. A. (1995). Using experiential learning theory and learning styles in diversity education. The importance of learning styles: Understanding the implications for learning Westport, USA course design, and education.

Redman, R. W., Lenburg, C. B., \& Walker, P. H. (1999). Competency assessment: Methods for development and implementation in nursing education. Online Journal of Issues in Nursing, 4(2), 1-7.

Ricketts, B. (2011). The role of simulation for learning within pre-registration nursing education - a literature review. Nurse Education Today, 31(7), 650-654.

Sullivan, R., \& McIntosh, N. (1996). The Competency -Based Approach To Training Medical Journal of Indonesia, 5(2), 95-98. doi:DOI: http://dx.doi.org/10.13181/mji.v5i2.853

Thanh, P. T. H. (2010). Implementing a student-centred learning approach at Vietnamese higher education institutions: Barriers under layers of Casual Layered Analysis (CLA) Journal of Futures Studies, 15(1), 21-38.

Uys, L. R., \& Gwele, N. S. (2005). Curriculum Development in Nursing. Process and Innovation. Newyork: Routledge. 
Van Horn, R., \& Freed, S. (2008). Journaling and dialogue pairs to promote reflection in clinical nursing education. . Nursing Education Perspectives, 29(4), 220-225.

Wall, P., Andrus, M. P., \& Morrison, P. (2014). Bridging the Theory Practice Gap through Clinical Simulations in a Nursing Under-Graduate Degree Program in Australia. International Journal of Learning, Teaching and Educational Research, 8(1), 127-135.

WHO. (2009). Nursing and Midwifery Human resources for Health: Global standards for the Initial Educaion of professional Nurses and Midwives. Retrieved from http://www.who.int/hrh/nursing_midwifery/en/

Zakari, N., Hamadi, H., \& Salem, O. (2014). Developing an understanding of researchbased nursing pedagogy among clinical instructors: A qualitative study. Nurse Education Today, 34(11), 1352-1356. doi:DOI: 10.1016/j.nedt.2014.03.011

Zhong, G., \& Xiong, X. (2010). Analysis of Factors Influencing Current Practice of Clinical Medicine Education. . Asian Social Science, 6(7), 189. doi:DOI: http://dx.doi.org/10.5539/ass.v6n7p189 